\title{
EL VALLE DE AYACUCHO Y EL TAWANTINSUYO
}

\author{
Lidio M. Valdez \\ J. Ernesto Valdez
}

\section{RESUMEN}

Este artículo está dirigido a fijar la situación del Valle de Ayacucho de la sierra central peruana, antes y durante la ocupación Inka. Hasta hace poco se argumentaba que este valle había sido abandonado durante la época Inka y, por tanto, no había jugado ningún rol dentro del Imperio Incaico. Sobre la base del nuevo trabajo de campo llevado a cabo en la porción norte del valle, se ha vuelto evidente que en la región había varios sitios importantes del período Inka. Antes de la conquista Inka los habitantes de la región ocupaban lugares establecidos en posiciones defensivas y, a menudo, las de más alta elevación. Realizada la conquista Inka, la mayoría de estos sitios fue reubicada en lugares de menor elevación. Al mismo tiempo, el estilo de cerámica local pre-Inka sobrevivió y continuó siendo manufacturado durante la época Inka, tal como lo indica su existencia en los sitios defensivos y en los de menor elevación. Los artefactos relacionados a los Inkas están presentes solamente en los sitios de menor elevación.

\section{ABSTRACT}

This paper is aimed to assess the situation of the Ayacucho Valley of the Peruvian central highlands before and during the Inka occupation. Until very recently, it was argued that this valley was largely abandoned during Inka times and consequently played no role within the Inka Empire. Because of new fieldwork carried out on the northern portion of the valley, it is becoming evident that in the region there were several important Inka period sites. Before the Inka conquest, the inhabitants of the region occupied sites established in defensive positions and often at higher elevation. Following Inka conquest, most of these sites were relocated to lower elevations. At the same time, the local pre-Inka pottery style survived and continued being manufactured during Inka times, as its occurrence at both defensive sites and low elevation sites indicates. Inka related artifacts, however, are present only at lower elevation sites.

Arqueología y Sociedad No 14, 2002: 77-98

Museo de Arqueología y Antropología

Universidad Nacional Mayor de San Marcos 
"Pasó adelante con sus banderas Pachacútic por el camino de Chinchansuyo, y sujetó las provincias de Vilcas, de los Soras y Lucanas con poco trabajo, por el poderoso ejército que llevaba, al cual no había nación que tuviese fuerzas para resistir. Mas, llegado a Guamanga, halló a sus naturales puestos en armas con resolución de defenderse, porque era gente muy belicosa e indómita y confiaban, no tanto en el número de combatientes en que eran muy inferiores al Inca, cuanto en la fortaleza de un peñol bien defendido por naturaleza, en que se habían encastillado. Sitiólos el Inca y túvoles en grande aprieto mucho tiempo, codicioso del señorio de tan rica y fértil provincia..." (Cobo 1956 [1653]: 80).

$\square^{\prime}$ 1 valle de Ayacucho de la sierra central del Perú (Figura 1), si bien fue una de las primeras regiones incorporadas al recientemente establecido estado Inka (Cieza de León 1967:163; Sarmiento de Gamboa 1956: 243), ha permanecido parcialmente al margen de toda discusión concerniente al Tawantinsuyo. Por un lado, la carencia de estudios específicos al respecto sugiere el poco interés de los especialistas en el tema en mención. Por otro lado, la aparente poca presencia de sitios pertenecientes a la época Inka tiende a indicar que el valle de Ayacucho fue parcialmente "despoblado" en tiempos del auge del estado Inka (ver Lumbreras 1975:225; MacNeish, Patterson y Browman 1975:74). Benavides Calle (1976), por ejemplo, en su Yacimientos Arqueológicos de Ayacucho sólo da referencia a tres sitios Inka (ver Valdez y Valdez 2000:15), mientras que MacNeish (1981) no da referencia a ningún asentamiento. En comparación con éstos, el número de sitios identificados como "Chanka" es relativamente superior, lo que estaría indicando que la conquista Inka resultó en un despoblamiento masivo del valle de Ayacucho.

El escaso interés mostrado por los especialistas al estudio de este periodo no necesariamente refleja la realidad del valle de Ayacucho dentro del Tawantinsuyo. Si bien estudios sistemáticos están todavía por inaugurarse, ya viene haciéndose cada vez más evidente que en este valle existieron importantes establecimientos pertenecientes a dicha época (Valdez 1999; Valdez y Valdez 2000). En efecto, los estudios etnohistóricos de Lorenzo Huertas (1998:14), por ejemplo, vienen indicando que la población del valle de Ayacucho durante la época Inka fue no sólo relativamente densa, sino también multiétnica (ver Stern 1982:20). Con el objetivo de contribuir a este capítulo poco conocido de la historia prehispánica del valle en mención, últimamente hemos emprendido nuevos estudios orientados a esclarecer la aún incierta situación de este valle antes y durante el apogeo del imperio Inka (Valdez y Valdez 2000). En este trabajo presentamos los avances de dichos estudios, y sobre la base de la información nueva acumulada durante los últimos años planteamos que la situación de dicho valle fue más compleja que lo sugerido originalmente. En la medida del progreso de nuestro trabajo y la recuperación de nuevos datos, los planteamientos aquí presentados seguramente serán modificados. Esperamos, sin embargo, que las ideas presentadas en este trabajo estimulen nuevos trabajos sistemáticos en la región.

\section{ESTUDIOS PREVIOS}

El valle de Ayacucho fue incorporado al dominio Inka corto tiempo después de la conquista de Vilkas (Cobo 1979:138; Rowe 1946:206). Puesto que, por un lado, Dorothy 


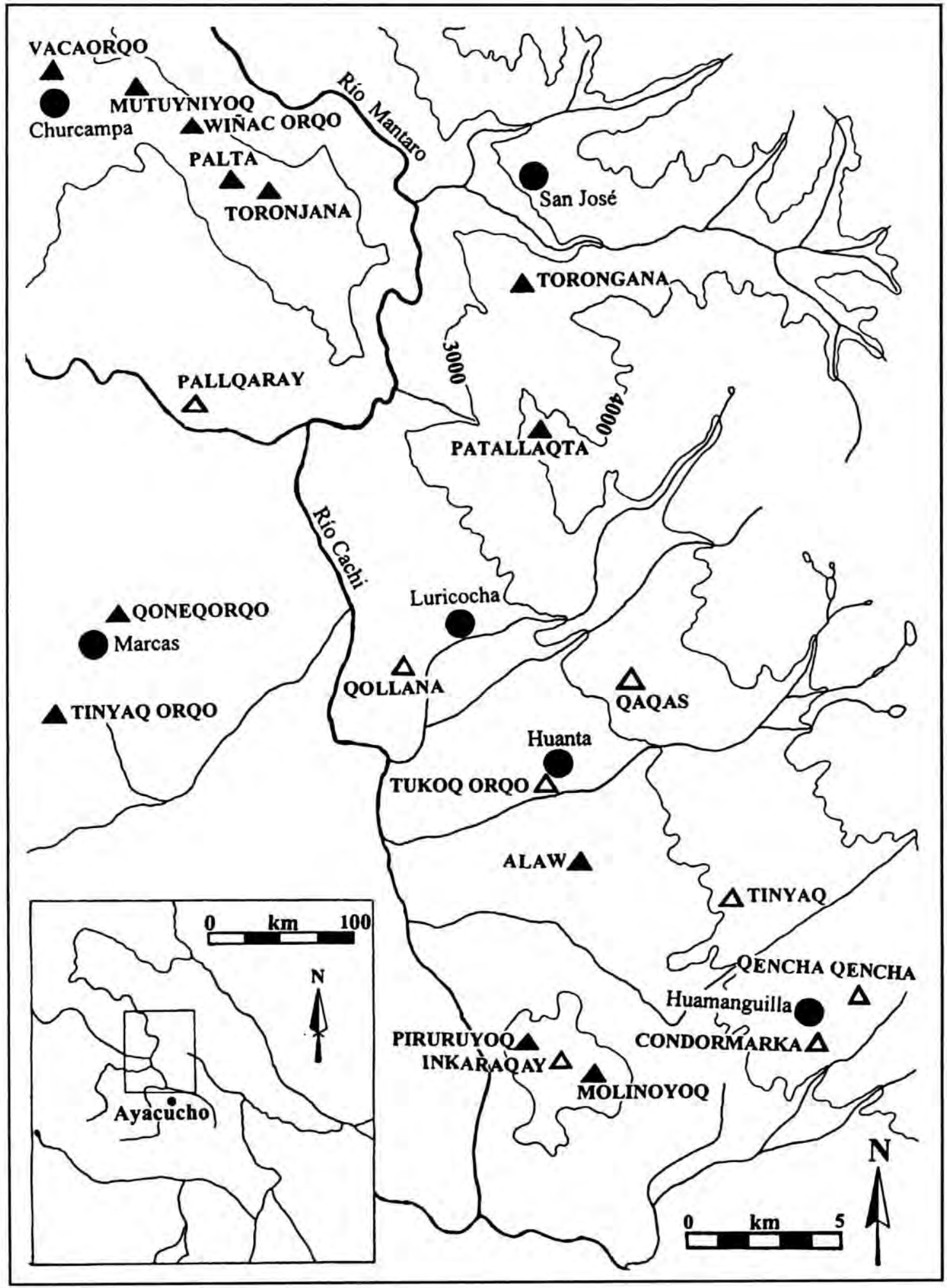

Figura 1. Ubicación de los asentamientos Inka y pre-Inka en el sector norte del valle de Ayacucho. 
Menzel (1959:126) estima que la conquista Inka de la costa sur ocurrió alrededor del año 1440 , y por otro, Terence D'Altroy (1987:78) sostiene que los Wankas fueron conquistados alrededor del año 1460 , es evidente que la incorporación de Vilkas debió haber ocurrido antes de 1440. De igual modo, la conquista del valle de Ayacucho debió haber antecedido a la conquista Wanka, especialmente considerando que este valle fue un paso necesario al antiguo territorio Wanka. No obstante esta temprana incorporación al control cusqueño, el valle de Ayacucho ha permanecido en el olvido de los especialistas sin justificación alguna.

Tal como hemos discutido en otro trabajo (Valdez y Valdez 2000:15), mucho de lo que se conoce acerca de la época Inka en el valle de Ayacucho está basado en fuentes etnohistóricas. Ellas señalan que realizada la conquista Inka en este valle fueron establecidos mitimaes antas y acos, ambos de origen cusqueño (Stern 1982; Urrutia 1985). Desgraciadamente, tales estudios no mencionan asentamientos específicos, excepto la indicación de que los mitimaes antas habrían sido reubicados en las inmediaciones de Huamanguilla. Una fuente excepcional es el reporte de Vaca de Castro (1908), que menciona la presencia de dos "tambos" para el valle de Ayacucho, aunque tampoco ofrece detalle alguno con respecto a la ubicación precisa de dichos establecimientos. Uno es referido como el "Tambo de San Juan de la Victoria" y el otro como el "Tambo de Yangar" (Vaca de Castro 1908:444-445). Este último, de acuerdo a la fuente en referencia, habría sido servido por los indios mitimaes de Diego Gavilán. De acuerdo con Cieza de León (1973:204-205), Azángaro era el repartimiento de Gavilán y estaba ubicado entre el río Parco y la ciudad de San Juan de la Victoria de Guamanga. Esta información, por lo tanto, sugiere que el Tambo de Yangar estaba ubicado en el valle de
Huanta, mientras que el Tambo de San Juan de la Victoria probablemente en el actual lugar donde se encuentra la ciudad de Huamanga. Cabe recordar que estos tambos formaron parte de una cadena de establecimientos similares ubicados a lo largo del camino real Inka que comunicó Cusco con el valle del Mantaro.

Entretanto, MacNeish (1981: figura 8-15) presenta la distribución de los asentamientos identificados como "Chanka", pertenecientes al periodo inmediatamente anterior a la conquista Inka. Benavides Calle (1976) también identifica un buen número de "sitios Chanka". En general, éstos no dejan de ser pocos, especialmente si se hace una comparación con el número de sitios identificados como Wari, por ejemplo. Estos datos, en conjunto, dan a entender que el valle de Ayacucho ya estaba relativamente despoblado durante el período inmediatamente anterior a la conquista Inka. Sin embargo, es importante insistir en que varios de los sitios clasificados como "Chanka" por MacNeish y Benavides Calle parecen no necesariamente pertenecer a la época pre-Inka; su identificación más parece estar basada en la presencia de una variedad de alfarería llana que, como se discute más adelante, no es un elemento diagnóstico confiable para identificar a los Chankas. Esto resta aún más el número de asentamientos identificables como Chanka, sugiriendo una cantidad poblacional todavía menor (Valdez 1999).

¿Fue el valle de Ayacucho efectivamente "abandonado" durante la época Inka? Ésta fue la principal interrogante que nos llevó a explorar el sector norte del valle de Ayacucho y a revisitar muchos de los sitios arqueológicos hasta entonces ubicados en la región. Nuestro trabajo se centró, primero, en hacer una evaluación superficial de los sitios identificados como Chanka e Inka. Luego, sobre la base de dicha información, se procedió con los trabajos de reconocimiento en 
la parte norte del referido valle. Producto de estas exploraciones es la identificación de Pallqaray, Qaqas, Tukoq Orqo, Alaw, Tinyaq, Qencha Qencha, Inkaraqay y Qollana, además de Condormarka, como sitios de la época Inka (Figura 1). Alaw fue inicialmente identificado como sitio "Chanka" (Benavides Calle 1976:183184), mientras que Tinyaq (Valdez y Valdez 2000) parece ser el mismo Qoriwillka de acuerdo a Benavides Calle (1976:95). El resultado inicial de esta evaluación es la presencia de un número considerable de asentamientos de la época Inka, la que hasta hace poco se limitaba a menos de 2 sitios. Junto a los sitios también están presentes numerosos sitios de ubicación defensiva, muchos de los cuales se encuentran al norte de la confluencia de los ríos Cachi y Mantaro, siempre a mayor distancia del fondo del valle, por encima de los 3800 msnm, y frecuentemente controlando zonas de difícil acceso y de amplia visibilidad.

\section{LOS SITIOS ARQUEOLÓGICOS}

\section{SITIOS DE LA ÉPOCA INKA}

La identificación de estos sitios como pertenecientes a la época Inka está basada en la evaluación tanto de la cerámica como de la arquitectura. Condormarka, Inkaraqay y Tinyaq, sitios más representativos para esta época en todo el valle, son reconocidos como pertenecientes a la época Inka, generalmente en razón de la arquitectura. Por ejemplo, Tinyaq presenta un tipo de arquitectura idéntico al de los depósitos Inka presentes a lo largo de la sierra central del Perú (Cieza de León 1973:198; Cobo 1956, 1979; D'Altroy 1992; D'Altroy y Earle 1992; Earle 1992; Hastorf 1993; Morris 1992; Morris y Thompson 1985). Además, y en conformidad con las observaciones de Cobo
(1956:124, 1979:218), por ejemplo, las estructuras de Tinyaq se encuentran en la cima de una colina; son rectangulares, con paredes bastante gruesas $(1 \mathrm{~m})$, y entre una estructura y otra siempre hay un espacio de aproximadamente $2 \mathrm{~m}$. Cobo sostiene que este espacio fue para controlar casos como el incendio, que de estar las estructuras juntas hubiese resultado en la destrución de todos los depósitos. El caso de los depósitos de Tinyaq ha sido discutido en mayor detalle en otro trabajo (Valdez y Valdez 2000), por lo que aquí no volveremos sobre ello; suficiente es señalar que Tinyaq consta de dos grupos alineados de estructuras rectangulares que cumplieron la función de almacenamiento.

Condormarka, ubicado en las inmediaciones de Huamanguilla, es uno de los pocos sitios donde tanto la arquitectura como la cerámica son Inka (Figura 2). Sin embargo, cerámica en el estilo local parece estar ausente en Condormarka. Durante las varias visitas hechas al sitio, también se ha notado la existencia de piedras trabajadas en el estilo propiamente Inka, y entre éstas destaca un ushno. A decir de Hyslop (1990:74, 99100), a lo largo del Tawantinsuyo los ushnus siempre aparecen en la parte central de los asentamientos (plazas), y como tal indican que su función fue de singular importancia dentro del esquema ritual Inka.

En efecto, Pizarro (165:192) menciona que en la misma plaza del Cusco había una "piedra redonda que tenían por ídolo, en mitad de la plaza...". Por cuanto durante el proceso de extirpación de idolatrías (ver Millones 1998) la iglesia trató de remover y/o eliminar los ushnus, es evidente que dichas estructuras fueron efectivamente parte primordial dentro de la cosmología religiosa Inka. Su presencia en Condormarka, por lo tanto, parece sugerir que éste fue uno de los pocos asentamientos Inka de mayor importancia de todo el valle de Ayacucho'. 


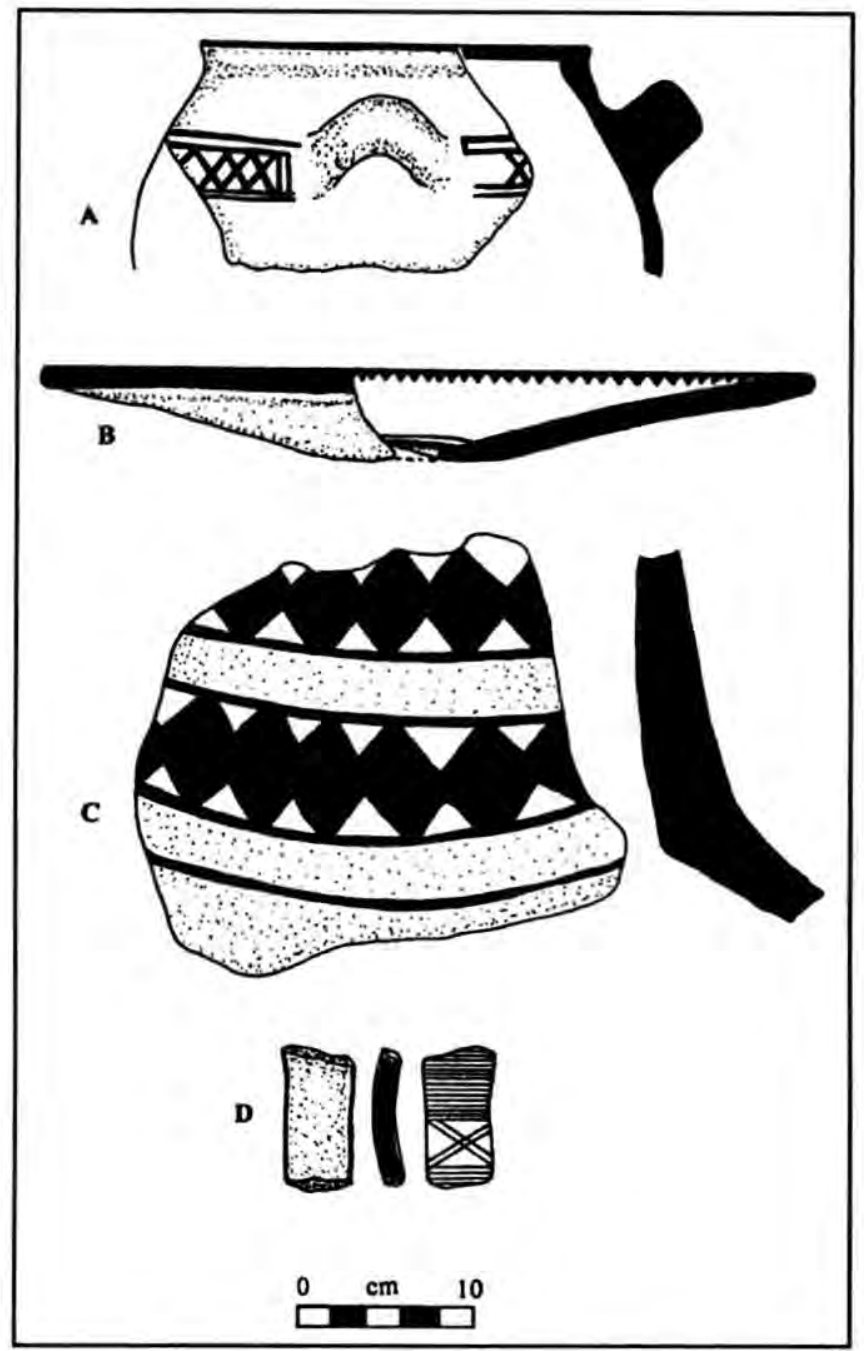

Figura 2. Cerámica Inka de Condormarka.

Por su parte, Qaqas, Qencha Qencha y Qollana son reconocidos como pertenecientes a la época Inka, principalmente tomando en cuenta la cerámica. Por ejemplo, en Qencha Qencha se ha recuperado cerámica Inka (Foto 1). Estos sitios son lugares de enterramiento pobremente conservados. Estudios posteriores en las inmediaciones de los entierros saqueados tal vez puedan exponer mejores evidencias en lo que se refiere al patrón mortuorio Inka en este valle.

Finalmente, el resto de los sitios son identificados como asentamientos de la época Inka por lo general en razón de la cerámica. En Pallqaray, por ejemplo, se han encontrado ejemplares completos de cerámica perteneciente a la época Inka (Foto 2 y Figura 3 ), aunque con fuerte influencia local. Junto a la muestra, también están presentes alfarerías identificables como Arqalla (Foto 3 y Figura 4) y Aya Orqo (Foto 4 y Figura 5). Por último, tanto en Alaw y Tukoq Orqo también se ha encontrado cerámica Inka, aunque siempre con fuerte influencia local. El significado de esta continuidad de la tradición local se discute más adelante.

\section{SITIOS FORTIFICADOS}

Duccio Bonavía (1964, 1969, 1970, 1972) fue el primero en registrar varios sitios arqueológicos al norte del valle de Ayacucho. Con la excepción del sitio de Arampana, que de acuerdo a Bonavía (1969:77, 1972:22) 


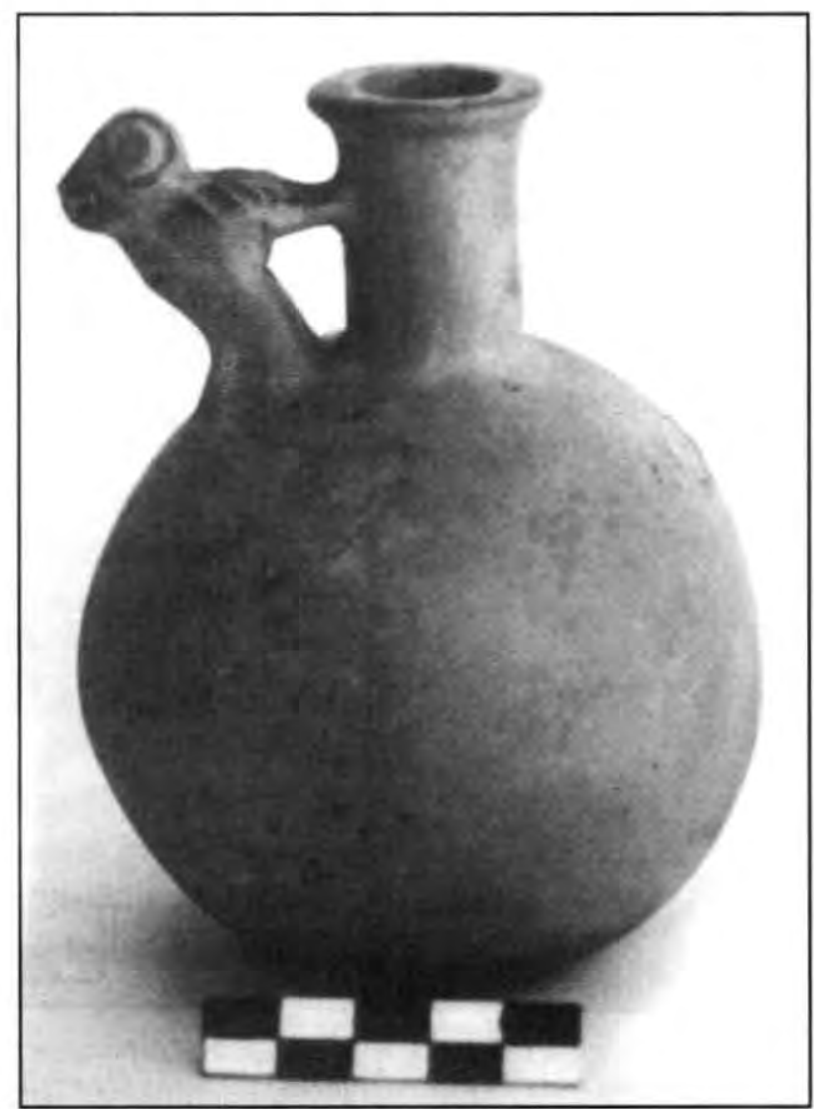

Foto I, Cerámica Inka procedente del sitio de Qencha Qencha (la escala está en centímetros).
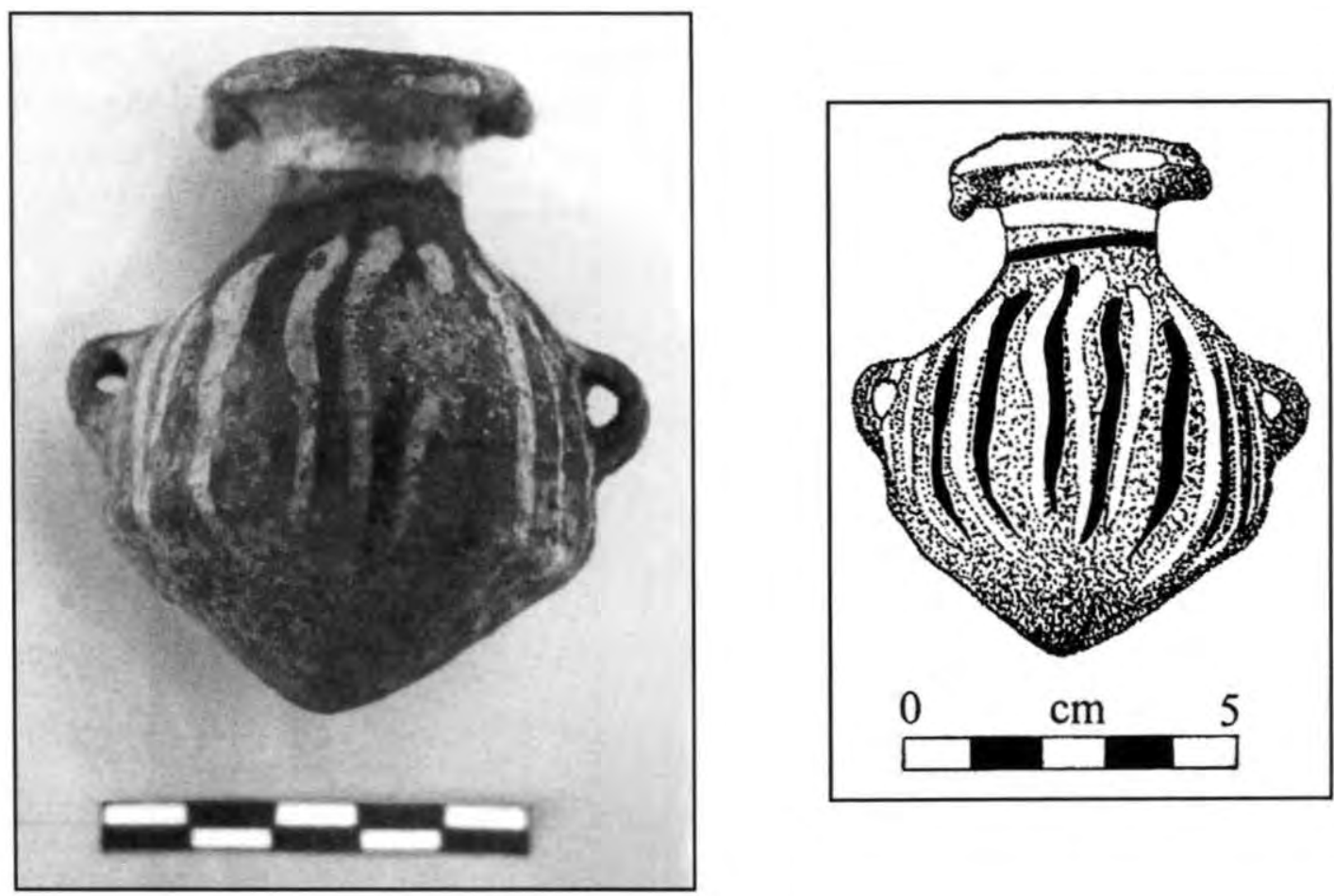

Foto 2 y Figura 3. Miniatura que representa un aríbalo Inka. Procede de Pallqaray (la escala está en centímetros). 

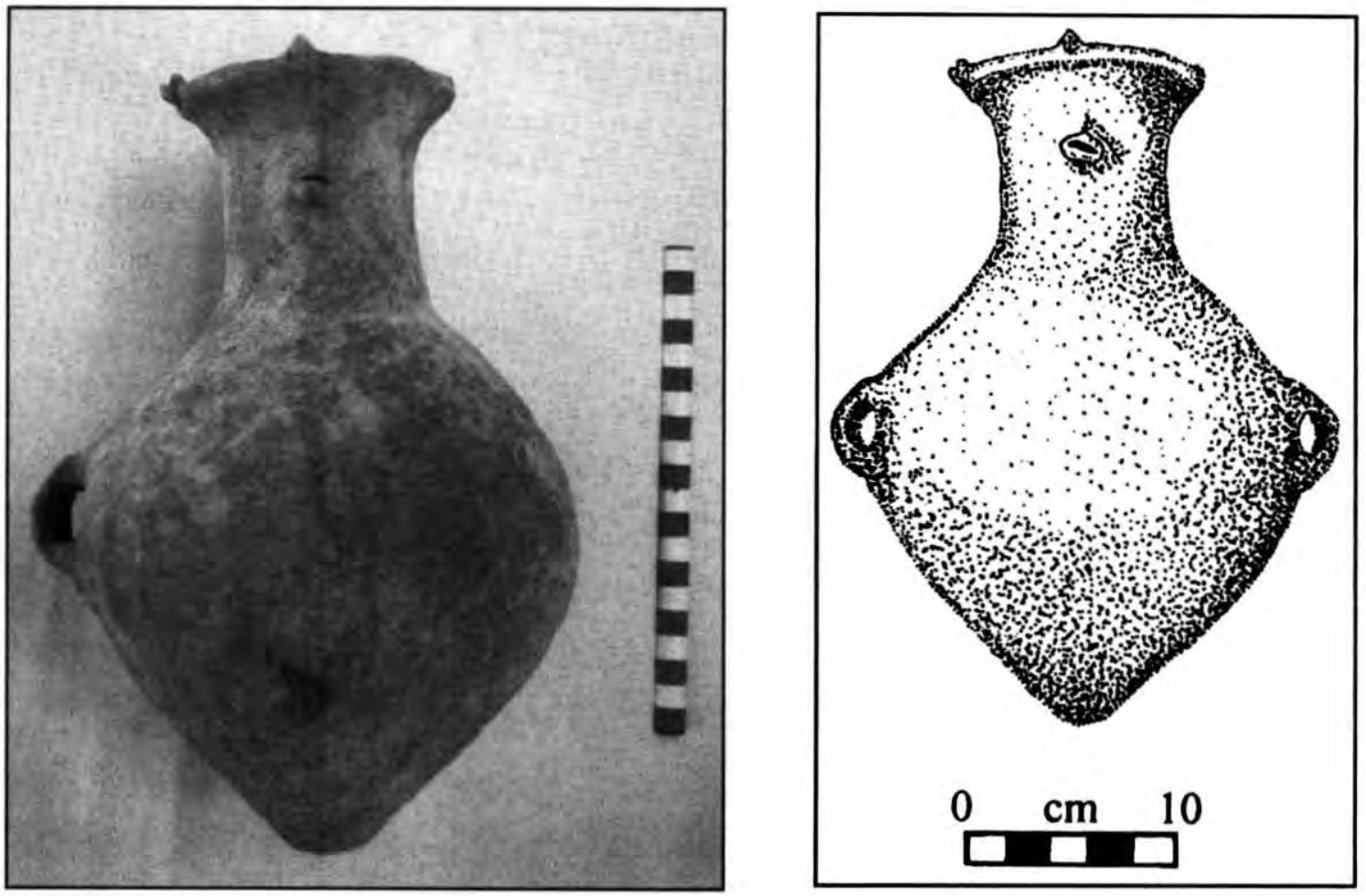

Foto 3 y Figura 4. Cerámica del estilo Arqalla procedente de Pallqaray (la escala está en centímetros).
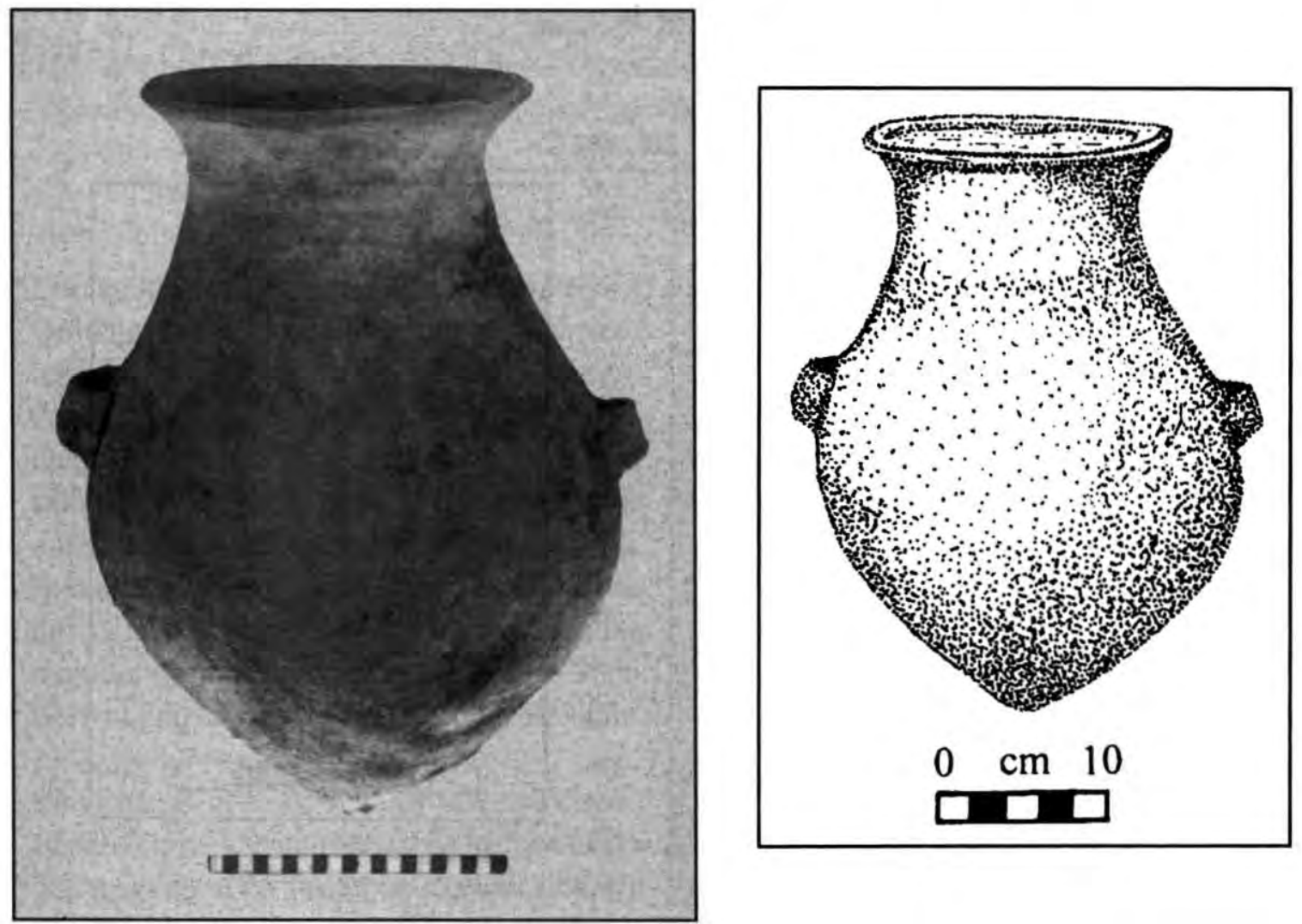

Foto 4 y Figura 5. Cerámica del estilo Aya Orqo procedente de Pallqaray (la escala está en centímetros). 
se encuentra sobre los $2370 \mathrm{msnm}$, otros sitios como Caballuyoq, Matukalli, Raqaraqay, Condoruchco, Uchuywamanga, entre otros, se encuentran en altitudes que superan los 3300 msnm (Bonavía 1964:22, 1969:76). Además, Bonavía (1970:78) resalta que muchos de estos sitios permanecen gran parte del tiempo cubiertos por la neblina, mientras que el sitio de Matukalli exhibe "un verdadero sistema defensivo, de probable tipo militar" (Bonavía 1969:78). Bonavía (1969:77) también notó que "todos los sitios presentan características idénticas", consistentes en estructuras de "forma circular" (Bonavía 1964:51). En general, Bonavía (1964:51) resaltó que todos estos sitios "obedecen al mismo patrón de ocupación consistente en construir en las puntas de los cerros evitando las laderas y las partes bajas". En la opinión del referido autor, "una necesidad de tipo estratégico, [habría sido] la que empujó a los constructores a buscar este tipo de hábitat, más aún si se toma en cuenta que hubo otros lugares más accesibles en la vecindad, sobre todo en las partes bajas..." (Bonavía 1969:82).

A base de una pobre colección de cerámica, Bonavía (1964:51, 1969:82, com. personal
2001) identificó los sitios arriba mencionados como pertenecientes a la época Inka. Con la diferencia de Caballuyoq, donde se encontró 3 tipos alfareros, la cerámica recuperada de los sitios arriba referidos fue identificada como Arqalla y Pataraqay (Bonavía 1969:82, 1970:259). Ambos estilos fueron inicialmente definidos por Lumbreras (1959) e identificados como cerámica Chanka. Bonavía $(1964,1969,1970)$, sin embargo, no tardó en expresar sus dudas acerca de la validez de la asociación del estilo Arqalla con los Chankas.

Recientemente hemos inspeccionado una sección del sector norte del punto de confluencia de los ríos Cachi y Mantaro y encontramos en ella varios sitios de ubicación defensiva. Uno de estos sitios se encuentra sobre la margen derecha del río Mantaro, en la cima del cerro Torongana y a una altitud de $3850 \mathrm{msnm}$. Al igual que en Molinoyoq (Foto 5), ubicado en la cima del cerro Allkowillka (ver González Carré y Gálvez Pérez 1987), en Torongana hay una cantidad aún no determinada de pequeñas estructuras de planta circular ( $2 \mathrm{~m}$ de diámetro), muchas de las cuales cubiertas por el ichu (Stepa ichu), vegetación típica de la zona

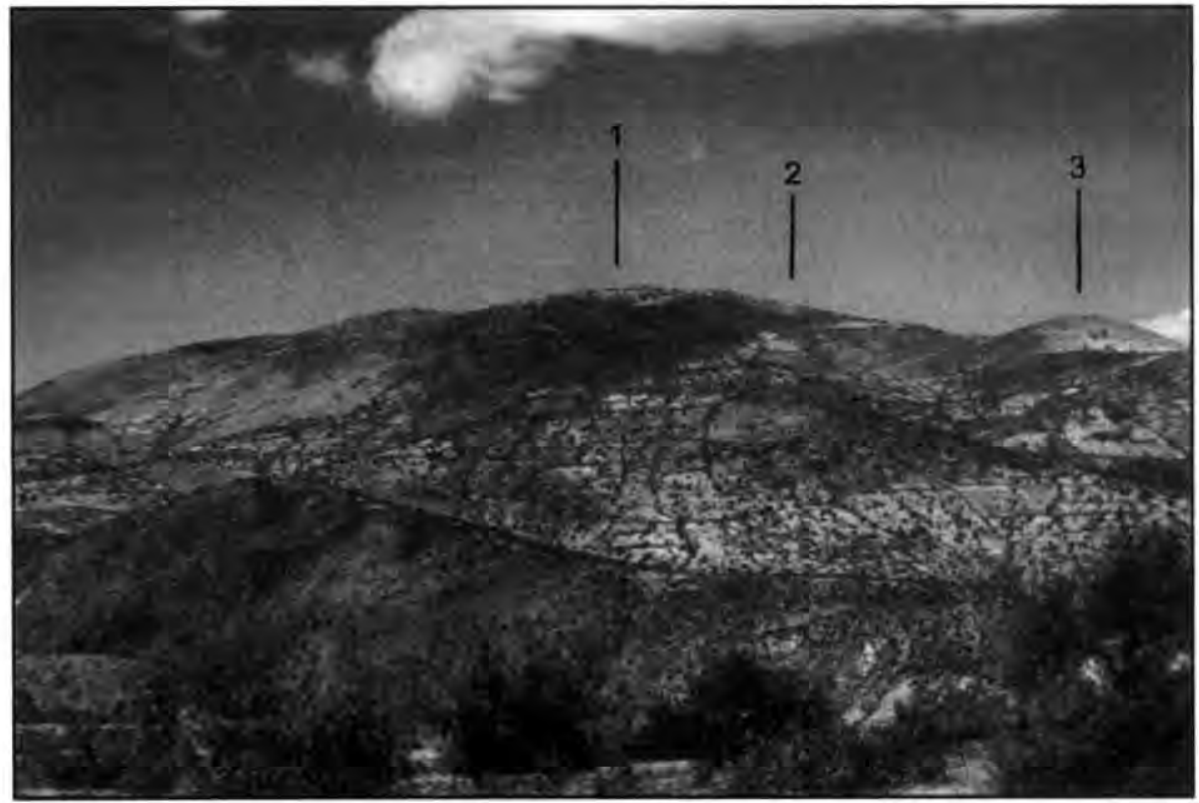

Foto 5. Ubicación de los sitios pre-Inka de Molinoyoq (1) y Piruruyoq (3) y del sitio Inka de Inkaraqay (2) (vista desde el lado norte). 
ecológica puna. En la parte central, el punto más elevado del lugar, sobresale un recinto rectangular y elevado que mide $18 \mathrm{~m}$ de largo y $10 \mathrm{~m}$ de ancho. A corta distancia al sur de Torongana se encuentra otro asentamiento contemporáneo, identificado como Patallaqta. Éste también ocupa la cumbre más alta, pero es bastante pequeño. Inicialmente MacNeish (1981) había reconocido a este sitio como una "fortificación".

Al lado opuesto del Torongana y controlando los puntos más altos de los cerros se encuentra un total de 4 sitios (Foto 6). El primero, el más extenso, es Toronjana, ubicado a una altitud de $3900 \mathrm{msnm}$. De la cumbre del cerro hay una fuerte pendiente que da hacia el lado este y noreste, mientras que al lado opuesto hay una superficie ligeramente inclinada; allí se encuentran aglutinadas numerosas estructuras de planta circular. Como en el caso de Torongana, en este sitio también está presente una estructura rectangular de 3 metros de altura (26 $\mathrm{m}$ de largo y $14 \mathrm{~m}$ de ancho), precisamente en la parte central y el punto más elevado del sitio. Delimitando el área donde se encuentran todas estas estructuras aparece un muro de aproximadamente $200 \mathrm{~m}$ de largo, cuya función probablemente fue defensiva.

A corta distancia al noroeste de Toronjana, se encuentra otro sitio de aspecto fortificado. Éste es Palta, sitio ubicado sobre los $3600 \mathrm{msnm}$ y en un lugar definitivamente de difícil acceso. En efecto, los lados este, oeste y sur del sitio son intransitables debido a la presencia de formaciones rocosas y pendientes de caída vertical. El acceso es posible sólo por el lado norte. Merece resaltar que en este sector se encuentra un largo muro que encierra varias estructuras aglutinadas de planta circular. Siguiendo hacia el norte encontramos los sitios de Wiñaq Orqo y Mutuyniyoq, ubicados sobre los 3700 y 3500 msnm, respectivamente. Aunque ambos son relativamente pequeños, no dejan de ofrecer el aspecto defensivo y la ubicación estratégica.

En las inmediaciones del actual poblado de Churcampa y ocupando la cumbre elevada del cerro Vacaorqo, se encuentra otro extenso asentamiento que comparte muchas características con los sitios previamente re-

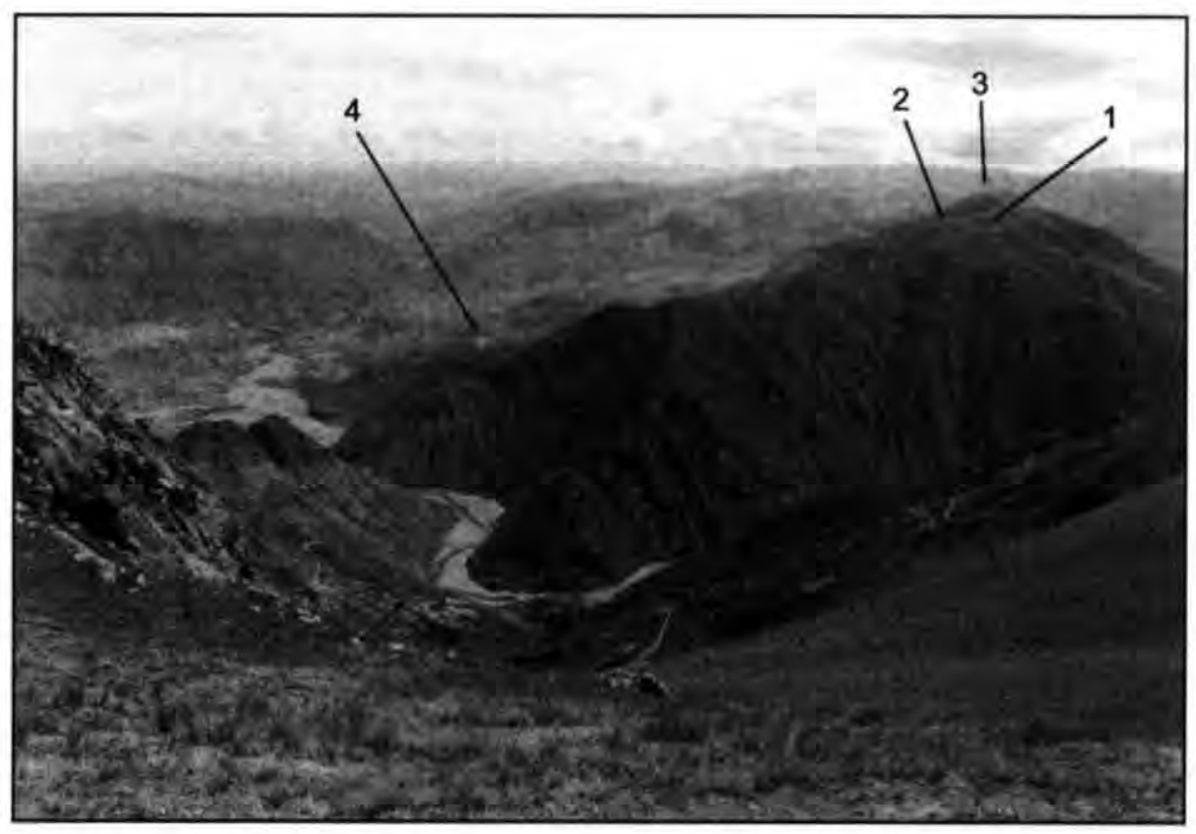

Foto 6. Ubicación de los sitios pre-Inka de Toronjana (1), Palta (2), Wiñaq Orqo (3) y del sitio Inka del Pallqaray (4). Nótese al fondo el río Mantaro (vista del lado sureste). 
feridos. En la cumbre y a una altitud de 4100 msnm hay una planicie rodeada de pendientes de caída perpendicular. En dicha superficie plana existen alrededor de 500 estructuras de planta circular y cuyo diámetro (interior) promedio es de $3 \mathrm{~m}$. Las estructuras están asociadas a varios corralones. Al igual que en Torongana, Toronjana y Palta, en Vacaorqo también se observa la presencia de una estructura rectangular de $35 \mathrm{~m}$ de largo y $19 \mathrm{~m}$ de ancho, la cual ocupa, una vez más, el punto más elevado del lugar. En virtud de su ubicación en la cima de un cerro bastante elevado y dotado de protecciones naturales, el lugar parece que fue elegido precisamente para garantizar la seguridad de sus habitantes.

En las cercanías del actual poblado de Marcas se encuentran 2 sitios arqueológicos que también comparten varios aspectos con los sitios hasta aquí referidos (ver Figura 1). El primero de estos es Qoneqorqo, ubicado en la cumbre del cerro del mismo nombre, a una altitud de $3400 \mathrm{msnm}$. El sitio consta de varias estructuras de planta circular, cuyo diámetro interior promedio es $4 \mathrm{~m}$. El otro sitio es Tinyaq Orqo, ubicado en las inmediaciones del pequeño poblado de San Isi- dro, a una altitud de $3400 \mathrm{msnm}$. Al igual que en el caso anterior, hay varias estructuras de planta circular en la cumbre del cerro, muchas de las cuales fueron habilitadas después de haberse construido terrazas para contrarrestar la pendiente. Si bien estos dos sitios no son espectaculares como los anteriores, tanto Qoneqorqo como Tinyaq Orqo no dejan de controlar las cumbres más elevadas y los puntos con mayor visibilidad de la región. Por ejemplo, desde ambos sitios es visible la sección norte del valle de Ayacucho.

En general, todos los sitios hasta aquí referidos, incluido Molinoyoq, tienen características comunes, las cuales son muy similares a las descritas por Bonavía (1964, $1969,1970)$. Por ejemplo, todos ocupan las cumbres altas de los cerros, lugares estos que ofrecen una amplia visibilidad y protección natural. En lugares donde el acceso es relativamente fácil, hay la presencia de grandes muros que posiblemente cumplieron una función defensiva. Éste es el caso, por ejemplo, de Molinoyoq (Foto 7). Entre las construcciones, de probable función defensiva, y las pendientes bastante pronunciadas se encuentran aglutinadas en núme-

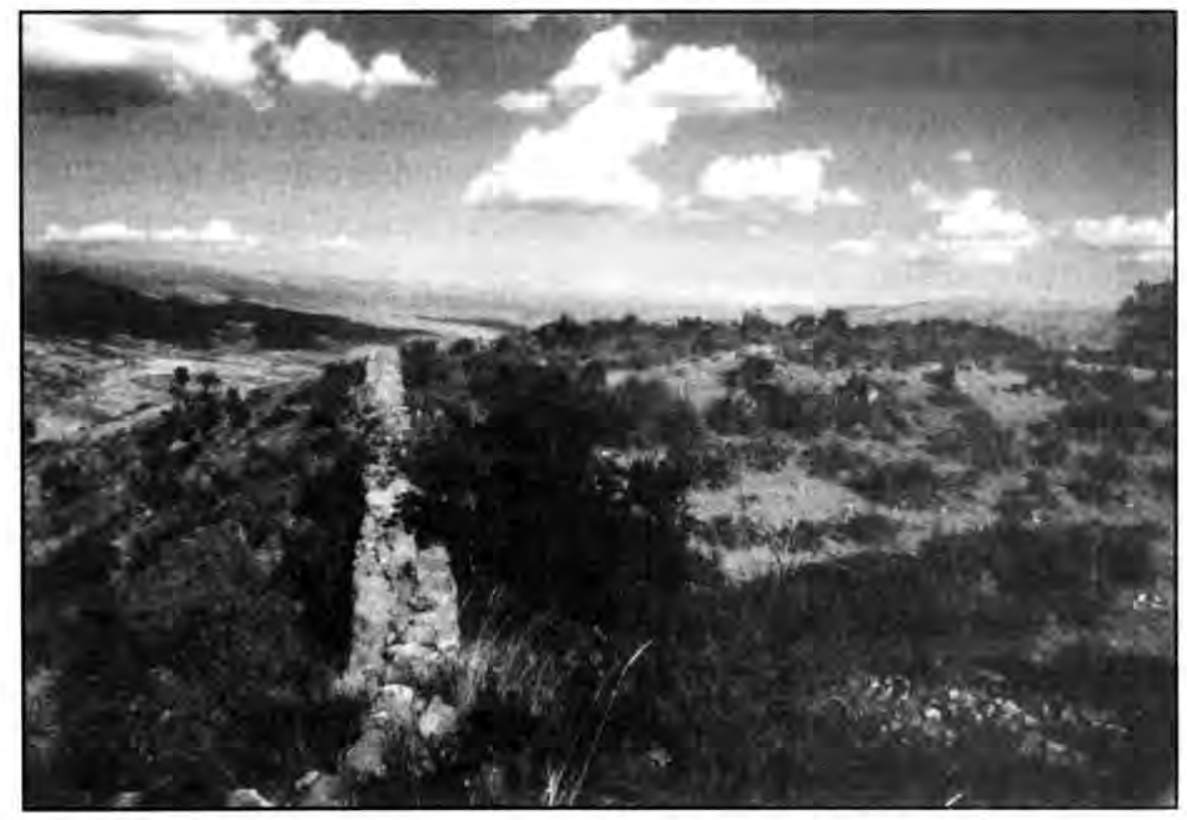

Foto 7. Muro del lado norte del sitio de Molinoyoq (vista de oeste a este). 
ro considerable pequeñas estructuras de planta circular. Esta sistemática ubicación de los sitios en los lugares más protegidos y con un control visual amplio del territorio circundante (por ejemplo, desde Molinoyoq se puede observar el lugar donde se encuentra Toronjana), desestimando lugares de fácil acceso y sobre todo el valle, da la posibilidad de que éstos fueron establecidos en tiempos de conflicto o, como señala Cobo (1956:80), para evitar la incursión Inka.

\section{EL PROBLEMA dE LA CERÁMICA}

Una de las interrogantes por responder es cuándo fueron establecidos exactamente los sitios fortificados. Lamentablemente, sigue siendo difícil dar una respuesta definitiva a esta pregunta, especialmente cuando se carece de evidencias estratigráficas y fechados de C14. Dada estas limitaciones, la única fuente de que se dispone es la cerámica. Sin embargo, en sitios como los mencionados en este trabajo es una tarea complicada, si no difícil, encontrar muestras diagnósticas de cerámica debido a la densa vegetación formada por el ichu. Además, la cerámica proveniente de sitios como Toronjana, Torongana y Vacaorqo es de pobre decoración o simplemente sin decoración, complicando así su identificación estilística.

No obstante estas dificultades y limitaciones, de cada sitio (excepto Patallaqta y Piruruyoq, este último ubicado en las cercanías de Molinoyoq [ver Figura 1 y Foto 5]) se logró recuperar una pequeña colección de cerámica. Esta cerámica es en general monocroma y varía muy poco de un sitio a otro. Estilísticamente los fragmentos de cerámica son reconocibles como Arqalla y Aya Orqo, ambos considerados como "alfarería Chanka" (Lumbreras 1959, 1975; González Carré 1992b). Para el caso de los sitios cercanos a Marcas están presentes fragmentos en el estilo Coras, también perteneciente al Periodo Intermedio Tardío (ver Matos 1966). Pero, siendo este periodo lo suficientemente amplio, queda aún incierto por ejemplo determinar si dichos sitios fueron establecidos luego de la caída de Wari, es decir, antes de la invasión Inka, o después de ésta.

Lumbreras (1975:219-220) sostiene que "la cerámica Aya Orqo tiene varias formas en común con la cerámica incaica..." González Carré, (1992b:59), al referirse a este grupo alfarero, también señala que "sus formas tienen estrecha relación con las formas Inka" y especula que "sus fabricantes ya estaban plenamente influenciados y relacionados con los artesanos cusqueños". Sin embargo, Aya Orqo es considerado como "cerámica Chanka" (González Carré 1992b:56). Merece insistir en que de acuerdo a Lumbreras (1975:202), en Aya Orqo, sitio donde se definió dicho grupo alfarero, se encontró cerámica "decorada de puro estilo cusqueño o Inka...”. Esta información da a entender que el sitio de Aya Orqo, y, por consiguiente, el grupo alfarero asociado a dicho sitio, pertenece a la época Inka. Lumbreras (1975) también menciona que Aya Orqo aparece en asociación con el grupo Arqalla, sugiriendo que este último también persistió durante la época Inka.

Desgraciadamente, el problema de la "cerámica Chanka" sigue siendo bastante complicado, y aunque existieron buenas intenciones en definir mejor su ubicación temporal (ver González Carré, et al. 1987; González Carré 1992b), estamos aún lejos de definir si aquélla es exclusivamente preInka (Valdez y Valdez 2000:21-22). Tal como hemos notado, por ejemplo, Bonavía (1970:278) sostiene que Arqalla es posiblemente Inka y no Chanka. Sin embargo, mientras no contemos con fechados absolutos esta controversia está lejos de ser resuelta. 
Mientras que Arqalla y Aya Orqo son los estilos que destacan en los sitios de ubicación defensiva, la alfarería de los sitios ubicados a menor ubicación, incluido Tinyaq (ver Valdez y Valdez 2000:21), también está compuesta de una cerámica de manufactura simple, identificable también como "Chanka". Éstos son Arqalla y Aya Orqo. Como se ha notado, Condormarka es el único sitio donde no se ha notado alfarería en la tradición local. Del mismo modo, y con la excepción de Tinyaq y Condormarka, el resto de los sitios identificados como pertenecientes a la época Inka exhiben construcciones de planta circular, forma constructiva también presente en los sitios de ubicación defensiva, como Piruruyoq, Molinoyoq, Toronjana, Torongana y Vacaorqo. Hasta hace poco, se ha venido acostumbrando identificar dichos sitios simplemente como "asentamientos Chanka" y la alfarería asociada a éstos como "cerámica Chanka". Como resultado, muchos sitios de tales características fueron a menudo identificados como "sitios Chanka" y su cerámica incluida dentro de la misma categoría. El hecho de que Alaw fue inicialmente identificado solamente como sitio "Chanka" corrobora esta observación.

Por ejemplo, MacNeish (1981:figura 8-15) presenta la distribución de los "asentamientos Chanka" del valle de Ayacucho ${ }^{2}$. Nuestra reciente reevaluación de algunos de estos asentamientos indica que en muchos de ellos hay otros grupos alfareros (Warpa, Wari) y junto a éstos encontramos cerámica de manufactura simple. Por lo tanto, la identificación de tales sitios como "Chanka" parece estar basada única y exclusivamente en la presencia de la referida cerámica. Pero, ¿es toda cerámica de pobre acabado necesariamente "Chanka" y en consecuencia preInka? En varios asentamientos Warpa y Wari hemos notado la presencia de alfarería de acabado simple, hecho que pone en duda la asociación temporal de la cerámica de po- bre acabado con el periodo que antecede a la conquista Inka. En otras palabras, en el valle de Ayacucho fue común la producción de alfarería simple antes de los Chankas; es precisamente por esta razón que resulta peligroso identificar dicha cerámica como "Chanka" y estrictamente pre-Inka.

Por cuanto el estilo Arqalla está presente por un lado en sitios fortificados, donde hay ausencia de elementos Inka, y por otro lado en sitios ubicados a menor elevación, donde es evidente la presencia de elementos Inka, parece probable que el referido estilo tiene una larga duración. En otras palabras, Arqalla parece que fue inicialmente manufacturado durante el Periodo Intermedio Tardío, alrededor de una fecha aún no determinada. Cuando esta región fue incorporada a la administración Inka dicho estilo continuó siendo producido. Su presencia en sitios de ubicación defensiva, donde precisamente aparece superficialmente separado de elementos Inka, sugiere que Arqalla fue producido antes de la conquista Inka. Sin embargo, la historia del mencionado estilo parece no terminar con el abandono de los sitios fortificados y la ocupación Inka. Por el contrario, los datos iniciales provenientes de Pallqaray, asentamiento de la época Inka ubicado en las inmediaciones de la confluencia de los ríos Mantaro y Cachi, sugieren que dicho estilo siguió siendo producido durante la época Inka. En Pallqaray, el estilo Arqalla (ver Foto 3 ) está presente pero en asociación a elementos propiamente Inka (ver Foto 2), lo que indica que tiene una larga tradición. Un hecho similar se ha notado en Tinyaq, establecimiento definitivamente asociado con el aparato administrativo Inka.

Siendo éste un probable escenario, el referido estilo no puede ser identificado exclusivamente como "cerámica Chanka", contrariamente a lo indicado por Lumbreras, como tampoco puramente Inka, a diferencia de lo señalado por Bonavía. El caso de 
Aya Orqo posiblemente es similar al de Arqalla, aunque la producción de este último parece haber sido más intensa durante la época Inka. Vasijas en el estilo Aya Orqo están presentes, además de Pallqaray (ver Foto 4), en Alaw (Foto 8), Inkaraqay y Tukoq Orqo. Por lo tanto, y como en el caso anterior, Aya Orqo tampoco puede ser reconocido como puramente pre-Inka o solamente Inka. Datos adicionales, como el análisis de los patrones de asentamiento, son necesarios para una mejor evaluación.

Para ofrecer una parcial solución al problema relacionado a la cerámica, es importante considerar regiones vecinas al valle de Ayacucho que han sido mejor estudiadas. Una de éstas es el valle del Mantaro. En este valle, y en la zona de Jauja, los continuos estudios de varios especialistas han permitido establecer una secuencia cronológica lo suficientemente sólida, que permite evaluar mejor los desarrollos ocurridos antes y durante la ocupación Inka. Está reconocido que muchos de los sitios pre-Inka de esta región se encuentran a menudo en lugares de ubicación estratégica (ver Earle et al. 1978:643; Matos 1966:96, 1978:313-314; Lavallée 1973:92; Lavallée y Julien 1983: 25-26; Dillon i983: 271-272; Hastorf 1990:266; Thoispson 1973:122). Los sitios, además, c stan de fortificaciones, lo que sugiere que la actividad bélica fue permanente durante esta época.

Datos provenientes de otras regiones presentan un panorama similar. Por ejemplo, de las cuencas formadas por los tributarios del río Pampas al sur del valle de Ayacucho, los sitios identificados como pre-Inka también aparecen en la cima de los cerros y siempre a modo de fortificaciones (ver Schreiber 1987:274; Valdez y Vivanco 1994:151-152). Para otras regiones, Hyslop (1990:149) presenta información parecida. Cabe recordar, además, que estos mismos autores, como Lavallée (1973) por ejemplo, son enfáticos al señalar que la ubicación de dichos sitios es estratégica y defensiva. Considerando que sitios como Molinoyoq, Torongana, Toronjana y Vacaorqo también mantienen una ubicación estratégica, existe una mayor posibilidad que dichos asentamientos sean pre-Inka.

Bernabé Cobo (1956:80) ofrece información adicional al mencionar que cuando el ejército Inka entró al valle de Ayacucho (Guamanga), halló a sus habitantes refugiados en "un peñol bien defendido". Dicho peñol pudo haber sido el sitio de Molinoyoq, ubicado precisamente en la parte media del valle. Hecho similar posiblemente también ocurrió con los habitantes del resto

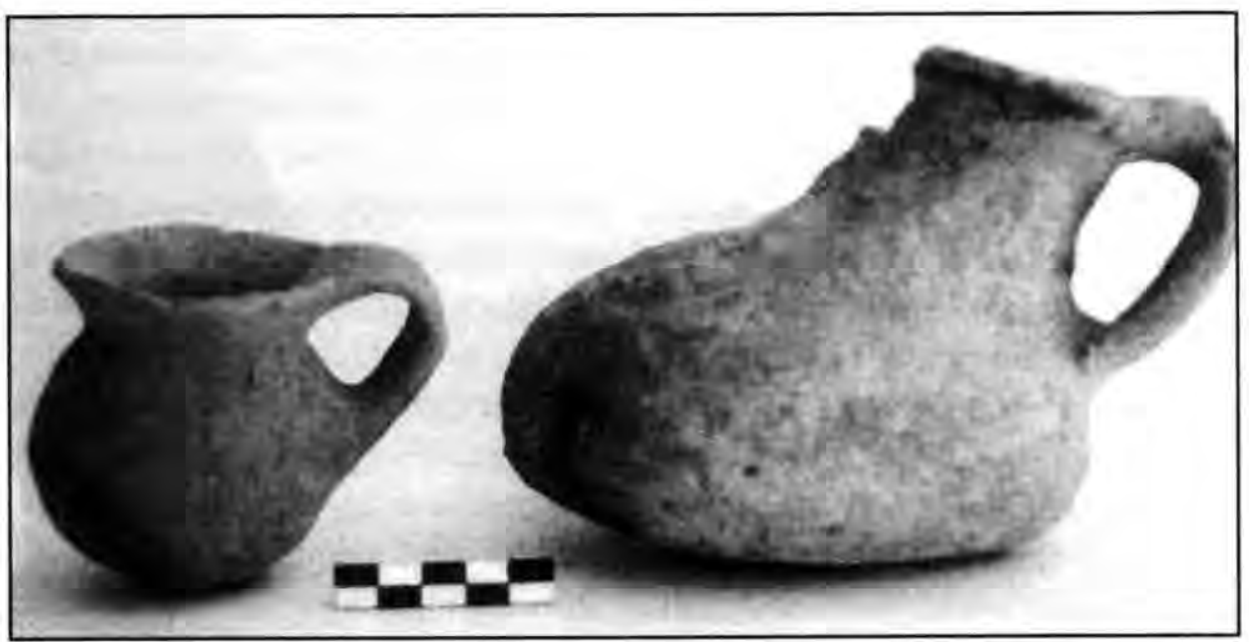

Foto 8. Cerámica del estilo Aya Orqo proveniente del sitio de Alaw (la escala está en centímetros). 
de los sitios referidos en este trabajo. De este modo, esta información sugiere que antes de la conquista Inka los asentamientos humanos del valle de Ayacucho y sus alrededores fueron edificados en lugares defensivos y estratégicos. Desde luego, un tema que requiere mayor análisis es la determinación de cuándo fueron establecidos inicialmente.

Por último, vale la pena destacar que diversos autores han observado una marcada diferencia entre la ubicación de los asentamientos pre-Inka y los sitios Inka. Los especialistas coinciden en que los sitios Inka a menudo se encuentran en los valles o cerca a los valles, pero definitivamente en lugares de menor elevación y menos defensivos (ver Costin y Earle 1989:693; Lavallée y Julien 1983:25; Seltzer y Hastorf 1990: 411; Schereiber 1987:274). En el área de nuestras investigaciones, los sitios que exhiben cerámica Inka también están ubicados a menor elevación, o precisamente en el mismo fondo del valle. Una excepción es Inkaraqay, ubicado en las inmediaciones de Molinoyoq (ver Foto 5).

Bonavía (com. personal, 2001) sostiene que sitios como Caballuyoq tal vez fueron ocupados por pueblos locales o mitimaes. Sin embargo, y como se ha anotado líneas adelante, muchos de los sitios estudiados por Bonavía también controlan lugares defensivos. Entonces, la interrogante es por qué esos probables establecimientos Inka están edificados en lugares defensivos. Desde luego, Bonavía también considera que estos sitios pudieron haber sido ocupados por poblaciones locales, aunque él insiste en que los sitios fueron habitados durante la época Inka. Estando las observaciones de Bonavía basadas en la evaluación de la alfarería, su posición deja abierta la posibilidad de que dicha alfarería tenga antecedentes locales.

\section{DISCUSIÓN}

De la información presentada líneas arriba, se desprende que antes de la conquista Inka existió un conjunto de asentamientos establecidos en zonas de difícil acceso, elegidas tal vez como lugares estratégicos para la defensa. Para el caso del valle de Ayacucho, además de Molinoyoq que efectivamente controla la cumbre más elevada del cerro Allkowillka, existieron varios asentamientos ubicados por lo general en la cima de los cerros. Siguiendo la conquista Inka todos estos asentamientos parecen haber sido despoblados y sus habitantes reubicados en lugares de menor elevación y con acceso directo al valle. En otros casos, las poblaciones fueron reestablecidas en nuevos asentamientos, que es el caso Molinoyoq. Sitios ubicados a menor elevación, como Alaw, sin embargo, parecen haber continuado siendo ocupados.

Dos de los mejores sitios que representan la época Inka en el valle de Ayacucho son Condormarka y Tinyaq. A diferencia del resto de los sitios, en Condormarka está presente alfarería Inka, lo que parece confirmar que éste fue un asentamiento intrusivo (de mitimaes) y cuya población debió haber sido foránea. Considerando que las fuentes ethnohistóricas mencionan la presencia de orejones cusqueños en las inmediaciones de Huamanguilla, y estando Condormarka cerca a esa localidad, es muy probable que Condormarka haya sido el lugar donde el grupo de orejones se estableció (Valdez y Valdez 2000:15). Al lado de estos sitios encontramos otros asentamientos donde la alfarería es generalmente simple y guarda mucha relación con la cerámica proveniente de los sitios defensivos. A diferencia de éstos últimos, sin embargo, en estos sitios hay evidencias Inka, o en su efecto fuerte influencia cusqueña. Un caso concreto es Pallqaray. 
La presencia de alfarería Arqalla y Aya Orqo en sitios como Pallqaray, en lugar de representar una ocupación Chanka y pre-Inka, más parece reflejar la continuidad de la tradición alfarera local y por lo tanto una continuidad poblacional. En otras palabras, en un buen número de sitios de esta época se continuó produciendo la así llamada "alfarería Chanka", pero desde luego como parte del sistema Inka. A todo esto probablemente se sumaron los varios grupos étnicos (mitimaes) referidos por Huertas (1981, 1989), quienes posiblemente llegaron a la región portando sus propias tradiciones alfareras. La identificación de dichas tradiciones alfareras, por lo tanto, es un reto que los especialistas debemos afrontar. Con esto, el estudio de las sociedades que coexistieron en el valle de Ayacucho durante la época Inka enriquecerá profundamente nuestro conocimiento acerca del rol y situación del valle de Ayacucho dentro del Tawantinsuyo.

Aquí es preciso recordar que hace ya varios años John Rowe (1946:200) hizo notar que la cerámica Inka nunca logró sustituir por completo a los estilos locales pre-inkas. Del mismo modo, los estudios de Dorothy Menzel (1959:127) en la costa sur han demostrado que muchos asentamientos del Horizonte Tardío muestran poco o nada de influencia Inka. John Hyslop (1990:244) también ha presentado varias instancias donde la administración Inka adoptó formas de construcción locales, hecho que es observable en el sitio Inka de Tambo Viejo del valle de Acarí (Menzel y Riddell 1986; Valdez 1996:39). Está bien reconocido, además, que el Tawantinsuyo fue conformado por pueblos y culturas diversas, que no sólo habitaron diversas regiones geográficas, sino que también se comunicaron en varios dialectos (ver Cobo 1979:189; Morris y Thompson 1985:10). Si bien esas tradiciones locales fueron conquistadas por los Inkas, éstas no fueron del todo alteradas y/ o sustituidas por la administración Inka; más bien, existen varios ejemplos donde las tradiciones locales, incluidos sus dialectos (Huertas 1998:10), sobrevivieron (véase D'Altroy 1992:197-199; Topic y Topic 1993:33). Morris y Thompson (1985:150), por ejemplo, hacen ver que en los alrededores de Huánuco Pampa, tal es el caso de los Chupaychos, la tradición local persistió durante la época Inka, desde luego adoptando algunos aspectos Inka. Un hecho similar parece que ocurrió en el valle de Ayacucho, donde la conquista Inka no resultó en profundos cambios de la tradición local. La alfarería ayacuchana, si bien adoptó algunos aspectos Inka, continuó su trayectoria sin sufrir cambios significativos.

El establecimiento del centro Inka de Vilkaswamán fuera del valle de Ayacucho (Cieza de León 1967:163) es de singular importancia. Esto parece sugerir que este valle ya había sido política y económicamente sustituido por la zona de Vilkas, lo que tal vez ocurrió después de la caída de Wari. Menzel (1959:129) sostiene que los Inkas frecuentemente utilizaron como sus capitales provinciales centros donde existía una autoridad central. Queda abierta la posibilidad de que la zona de Vilkas haya sido el eje político de mayor importancia al momento de la llegada Inka. La mayor presencia de asentamientos Chanka en dicha región (González Carré et al. 1987) así lo sugiere.

\section{CONCLUSIÓN}

En este trabajo discutimos un tema que, no obstante su importancia para comprender mejor la política expansiva del estado Inka, ha sido dejado al margen por los especialistas. De acuerdo con los más recientes trabajos arqueológicos, es evidente la presencia de varios asentamientos pertenecientes a la época Inka en el valle de Ayacucho, muchos de los cuales están en el fondo del valle. Antes de la incursión Inka, parece evidente 
que los asentamientos fueron por lo general, si no exclusivamente, establecidos en lugares defensivos y a menudo sobre los $3800 \mathrm{msnm}$. Una dificultad aún por determinar es conocer exactamente cuándo fueron establecidos. Con la llegada Inka, asentamientos parecen haber sido despoblados, al ser sus ocupantes reubicados en lugares menos defensivos y sobre todo cerca al fondo del valle.

Nuestro trabajo también sugiere que la "cerámica Chanka" no parece representar exclusivamente una ocupación pos-Wari y preInka como se creía hasta hace poco. Por el contrario, existe la posibilidad de que esta tradición local siguió existiendo durante la época Inka, proyectándose tal vez hasta la época colonial. El caso en consideración es la presencia de los estilos Arqalla y Aya Orqo tanto en los sitios defensivos como en aquellos que denotan material definitivamente Inka. Futuros trabajos y sobre todo un mejor estudio de la así considerada "cerámica Chanka" probablemente revelarán nuevas evidencias en esta dirección, y sólo así podremos esclarecer este capítulo aún oscuro de la historia prehispánica del valle de Ayacucho. Junto a esto, se hace indispensable la identificación de los varios grupos étnicos de la época Inka referidos por los historiadores. Todo esto es un reto difícil, pero sabemos que éstos son los aspectos que hacen la investigación arqueológica interesante.

La complejidad del periodo Inka -distintos grupos étnicos- y la continuidad de la tradición alfarera pre-Inka durante el periodo Inka, complican por ejemplo la fácil distinción de los sitios pre-Inka y aquellos que pertenecen a la época Inka utilizando la alfarería. Todo esto se hace todavía más complejo cuando desde la perspectiva arqueológica las épocas Inka y pre-Inka en este valle siguen desconocidas. Por tanto, sigue por determinarse el número de asentamientos que los Inkas encontraron en el valle de
Ayacucho al momento de la conquista. Los datos iniciales indican que éstos eran muy pocos, y definitivamente más escasos que los inicialmente sugeridos por MacNeish (1981).

En síntesis, todo análisis de la ocupación Inka del valle de Ayacucho debe tener en cuenta que el estado Inka no fue un aparato centralizado y menos una entidad totalitaria. Se debe reconocer que la administración estatal Inka sí modificó profundamente el comportamiento de las culturas conquistadas en varias maneras, ya sea haciéndolas más productivas (LeVine 1987:40), o ya sea reubicándolas mediante el sistema de mitimaes (Cobo 1979:189). Sin embargo, el estado, al incorporar por ejemplo autoridades locales al sistema de gobierno Inka (D'Altroy 1987), también permitió la pluralidad étnica y la conservación de las tradiciones locales hasta entonces existentes. Por consiguiente, al estudiar sistemas de gobierno como el Inka no se debe pensar en homogeneidad cultural, y mucho menos esperar la existencia de evidencias similares entre una región y otra. En muchos lugares la ocupación Inka no necesariamente está representada por alfarería Inka; por el contrario, las tradiciones locales persistieron, en algunos casos incluso hasta muchos años después de la conquista española. Éste es uno de los grandes retos que los especialistas debemos aceptar y considerar como parte de nuestros proyectos de investigación. Reconocemos, por último, que las nociones presentadas en este trabajo no pretenden ser soluciones finales. Apenas hemos empezado a identificar los sitios de la época Inka en un valle que promete ser de mucho interés. Definitivamente, hay mucho que hacer para poder comprender y reflexionar mejor acerca de la situación de este valle dentro del esquema imperial Inka. Dicho esto, esperamos que las ideas y observaciones presentadas en este ensayo sirvan como punto de partida para iniciar un análisis más profundo del tema. 


\section{AGRADECIMIENTO}

Nuestro más sincero reconocimiento a David Romaní y Teodardo Jaime por su continua y desinteresada colaboración durante los varios trabajos de reconocimiento.

Los trabajos arqueológicos sobre las cuales se basa este trabajo fueron llevados a efecto gracias a una beca posdoctoral otorgada al primer autor por la Social Sciences and Humanities Research Council of Canada (756-98-0016), por lo cual expresa aquí su agradecimiento. Las opiniones vertidas en este trabajo, desde luego, no son del Council, sino únicamente de los autores.

Por último, dedicamos este trabajo a los habitantes del valle de Ayacucho, en quienes siempre encontramos estímulo y sobre todo valiosa información antropológica.

\section{NOTAS}

' Desgraciadamente, Condormarka viene siendo rápidamente destruido, mientras que las autoridades del Instituto Nacional de Cultura hacen poco o nada para detener la irreparable pérdida de un sitio que a nuestro entender es el único de su naturaleza en todo el valle de Ayacucho.

${ }^{2}$ Entre los sitios Chanka, MacNeish (1981: figura 8-15) identificó al sitio 494 como un "asentamiento fortificado". Recientemente hemos logrado visitar el sitio, que efectivamente se encuentra en la cumbre más alta y es identificado por los vecinos de zonas inmediatas como Patallaqta. Sin embargo, en el sitio hemos encontrado apenas dos estructuras circulares, las cuales están asociadas a dos corralones que no tienen nada de fortificación. En general, éste es sólo un pequeño asentamiento. 


\section{BIBLIOGRAFÍA}

BENAVIDES, Mario

1976 Yacimientos arqueológicos de Ayacucho. Universidad de Huamanga, Ayacucho.

BONAVÍA, Duccio

1964 "Investigaciones en la ceja de selva de Ayacucho". Arqueológicas 6: 1-65.

1969 "Núcleos de población en la ceja de selva de Ayacucho (Perú)", en El proceso de urbanización en América desde sus orígenes hasta nuestros días (J. E. Hardoy \& R. P. Schaedel, eds.), pp. 75-83. Instituto Torcuato Di Tella, Buenos Aires.

1970 "Investigaciones arqueológicas en el Mantaro medio". Revista del Museo Nacional 35: 211-291.

1972 Reconocimiento arqueológico en el área del Mantaro. Arqueológicas 14: 1140.

CIEZA DE LEÓN, Pedro

1967 El Señorío de los Incas. Instituto de Estudios Peruanos, Lima.

1973 La Crónica del Perú. Ediciones Peisa, Lima.

COBO, Bernabé

1956 [1653] Historia del Nuevo Mundo, en Obras del Padre Bernabé Cobo, Vol. 2, pp. 5-275. Biblioteca de Autores Españoles, Tomo XCII. Ediciones Atlas, Madrid.

1979 History of the Inca Empire. University of Texas Press, Austin.

COSTIN, Cathy L. y Timothy EARLE 1989 "Status distinction and legitimation of power as reflected in changing patterns of consumption in late prehispanic Peru". American Antiquity 54 (4): 621-719.
DILLON, Paul H.

1983 "The Chancas of Angaraes: 1450 (?) - 1765", en Investigations of the Andean Past (D.H. Sandweiss, ed.), pp. 268-290. Latin American Studies Program, Cornell University, Ithaca, New York.

\section{D'ALTROY, Terence N.}

1987 "Transition in Power: centralization of Wanka political organization under the Inka role". Ethnohistory 34: 78-102.

1992 Provincial Power in the Inka Empire. Smithsonian Institution Press, Washington, D.C.

D'ALTROY, Terence N. y Timothy K. EARLE

1992 "Inka storage facilities in the upper Mantaro Valley, Peru", en Inka Storage Systems (T. Y. LeVine, ed.), pp. 176-205. University of Oklahoma Press, Norman.

EARLE, Timothy K.

1992 "Storage and the Inka imperial economy: archaeological research", en Inka Storage Systems (T. Y. LeVine, ed.), pp. 237342. University of Oklahoma Press, Norman.

EARLE, Timothy K., Terence D'ALTROY, \& J. LeBLANC

1978 "Arqueología regional de los periodos prehispánicos tardíos en el Mantaro". Actas y Memorias del III Congreso Peruano del Hombre y la Cultura Andina II: 645-672, Lima.

GONZÁLEZ, Enrique

1992a Historia Prehispánica de Ayacucho.

Universidad de Huamanga, Ayacucho.

1992b Los Señoríos Chankas. Universidad de Huamanga e Instituto Andino de Estudios Arqueológicos, Lima. 
GONZÁLEZ, Enrique y José GÁLVEZ 1987 Molinuyoq: terrazas y reservorios en un pueblo prehispánico de Ayacucho. Boletín de Lima 53: 19-24.

GONZÁLEZ, Enrique, Denise POZZIESCOT, Muriel POZZI-ESCOT y Cirilo VIVANCO

1987 Los Chankas: cultura material. Universidad de Huamanga, Ayacucho.

HASTORF, Christine A.

1990 "The effect of the Inka State on Sausa agricultural production and crop consumption". American Antiquity 55: 262-290.

1993 Agriculture and the Onset of Political Inequality before the Inka. Cambridge University Press, Cambridge.

HUERTAS, Lorenzo

1981 "Poblaciones indígenas en Huamanga Colonial", en Etnohistoria y Antropología Andina (A. Casenelli et al., eds.), pp. 131144. Museo Nacional de Historia, Lima.

1998 "Conformación del espacio social en Huamanga, siglos XV y XVI", en Historia, Religión y Ritual de los Pueblos Ayacuchanos (L. Millones, H. Tomoeda \& T. Fujii, eds.), pp. 7-28. Senri Ethnological Reports 9, National Museum of Ethnology, Osaka.

HYSLOP, John 1990 Inka Settlement Planning. University of Texas Press, Austin.

LAVALÉE, Danielle

1973 "Estructura y organización del hábitat en los Andes centrales durante el Periodo Intermedio Tardío". Revista del Museo Nacional 39: 91-116.

LAVALLÉE, Danielle \& Michele JULIEN 1983 Asto Curacazgo Prehispánico en los Andes Centrales. Instituto de Estudios Peruanos, Lima.
LeVINE, Terry Y.

1987 "Inka labor service at the regional level: the functional reality". Ethnohistory 34: 14-46.

LUMBRERAS, Luis G.

1959 "Esquema arqueológico de la sierra central del Perú". Revista del Museo Nacional 28: 64-117.

1975 Las Fundaciones de Huamanga. Club de Huamanga, editores, Lima.

MacNEISH, Richard S.

1981 "Synthesis and Conclusions", en Prehistory of the Ayacucho Basin, Peru, Vol. 2 (R. S. MacNeish, ed.), pp. 199-250. The University of Michigan Press, Ann Arbor.

MacNEISH, Richard S., Thomas C. PATTERSON y David L. BROWMAN

1975 The Central Peruvian Prehistoric Interaction Sphere. Papers of the R.S. Peabody Foundation for Archaeology, Volume 7, Phillips Academy, Andover.

\section{MATOS, Ramiro}

1966 "La economía durante el periodo de los reinos y confederaciones en Mantaro". XXXV Congreso Internacional de Americanistas, Vol. 2: 95-99. Sevilla.

1978 "The cultural and ecological context of the Mantaro Valley during the Formative period", en Advances in Andean Archaeology (D. L. Browman, ed.), pp. 307-25. Mounton, Chicago.

MENZEL, Dorothy 1959 "The Inca occupation of the South Coast of Peru". Southwestern Journal of Anthropology 15 (2): 125-142.

MENZEL, Dorothy y Francis A. RIDDELL 1986 Archaeological Investigations at Tambo Viejo, Peru, 1954. California Institute for Peruvian Studies, Sacramento. 
MILLONES, Luis

1998 "Logros y azares de la cristianización colonial: el obispado de Huamanga", en Historia, Religión y Ritual de los Pueblos Ayacuchanos (L. Millones, H. Tomoeda \& T. Fujii, eds.), pp. 29-49. Senri Ethnological Reports 9, National Museum of Ethnology, Osaka.

\section{MORRIS, Craig}

1992 "The technology of highland Inka food storage", en Inka Storage Systems (T. Y. LeVine, ed.), pp. 237-258. University of Oklahoma Press, Norman.

MORRIS, Craig y Donald E. THOMPSON 1985 Huánuco Pampa: an Inca City and its Hinterland. Thames and Hudson, London.

PIZARRO, Pedro

1965 [1571] Relación del Descubrimiento y Conquista de los Reinos del Perú, en Crónicas del Perú V, pp. 159-242. Biblioteca de Autores Españoles, Tomo CLXVIII, Ediciones Atlas, Madrid.

ROWE, John H.

1946 Inca culture at the time of the Spanish conquest, en Handbook of South American Indians, Vol. 2 (J. H. Steward, ed.), pp. 183330. Smithsonian Institution Bureau of American Ethnology Bulletin 143, Washington, D.C.

\section{SARMIENTO DE GAMBOA, Pedro} 1965 [1552] Historia Indica, en Obras Completas del Inca Garcilaso de la Vega, pp.193279. Biblioteca de Autores Españoles, Tomo CIIIV. Ediciones Atlas, Madrid.

SELTZER, Geoffrey. O. y Christine A. HASTORF

1990 "Climatic change and its effect on prehistoric agriculture in the Central Peruvian Andes". Journal of Field Archaeology 17: 394-414.
SCHEREIBER, Katharina J.

1987 "Conquest and consolidation: a comparison of the Wari and Inka occupation of a highland Peruvian Valley". American Antiquity 52: 266-284.

\section{STERN, Steve J.}

1982 Peru's Indian Peoples and the Challenge of Spanish Conquest: Huamanga to 1640. University of Wisconsin Press, Madison.

\section{THOMPSON, Donald E.}

1973 "Investigaciones arqueológicas en los Andes orientales del norte del Perú". Revista del Museo Nacional 34: 117-125.

TOPIC, John R. y Theresa L. TOPIC 1993 "A summary of the Inca occupation of Huamachuco", en Provincial Inca: Archaeological and Ethnohistorical Assessment of the Impact of the Inca State (M. A. Malpass, ed.), pp. 17-43. University of Iowa Press, Iowa City.

\section{URRUTIA, Jaime}

1985 Huamanga: Región e Historia 1536

- 1770. Universidad de Huamanga, Ayacucho.

VACA DE CASTRO, Cristóbal 1908 [1543] Ordenanzas de Tambos. Revista Histórica, Tomo III, No. 4: 427-492. Instituto Histórico del Perú, Lima.

VALDEZ, Lidio M.

1996 Los depósitos Inka de Tambo Viejo, Acarí. Tawantinsuyo 2: 37-43.

1999 "The Inka State and the Ayacucho Valley, Peru". Ponencia presentada al 18th Annual Northeast Conference on Andean Archaeology and Ethnohistory, University of Massachusetts, Amherst. 
VALDEZ, Lidio M. y J. Ernesto VALDEZ VALDEZ, Lidio M. y Cirilo VIVANCO 2000 "Los sistemas de almacenamiento Inka de Tinyaq, Ayacucho, Perú". Bulletin de l'Institut Français d'Etudes Andines 29 1994 "Arqueología de la cuenca del Qaracha, Ayacucho, Perú". Latin American (1): 13-27.

Antiquity 5: 144-157. 